\title{
AVALIAÇÃO DE ERROS DE MEDICAÇÃO ESTUDO DE CASO COM PROFISSIONAIS DA SAÚDE DE CAJAZEIRAS-PB.
}

\author{
Juliana Saraiva de Alencar $^{1}$; Lorena Saraiva de Alencar $^{2}$; Joseana Maria Saraiva ${ }^{3}$; Gilberto Santos Cerqueira ${ }^{4}$
}

\begin{abstract}
Resumo
Os erros de medicação fazem parte da realidade mundial e estão presentes nas instituições de saúde e chegam a acometer tanto o setor público quanto privado. Sua ocorrência causa sérios problemas aos pacientes, desde incapacidades até a morte. O objetivo deste trabalho foi identificar as causas e fatores que contribuem para ocorrência de erros de medicação em instituição hospitalar pública. Foi realizado um estudo exploratório descritivo, com abordagem qualitativa em um hospital público da cidade de Cajazeiras-PB. Para coleta de dados foi utilizado um questionário estruturado, com questões abertas e fechadas, nas questões abertas foi utilizado um gravador digital. Após as gravações, as entrevistas foram transcritas. A amostra foi composta por 34 profissionais de enfermagem. Para análise dos dados foi utilizada a metodologia de Trivinos (2006). Os resultados apresentados mostram que a maioria dos entrevistados são do sexo feminino, com faixa etária predominante entre 20 e 29 anos, com tempo de trabalho menor que 2 anos (44,1\%), 44,1\% apresentam o $2^{\circ}$ grau completo e 76,4\% com renda entre 1 a 3 salários. Para grande parte dos entrevistados, o erro de medicação está associado à ilegibilidade da caligrafia médica, sobrecarga de trabalho e falta de conhecimento teórico e prático. A caligrafia médica nas prescrições dificulta o trabalho da enfermagem, o que torna necessária uma modificação no sistema, a partir do uso de prescrições eletrônicas, maior contratação de profissionais, realização de cursos de reciclagem, todas estas medidas tomadas com o objetivo de reduzir ou prevenir os erros.
\end{abstract}

Palavras-chaves: Erro, Medicação, Enfermagem.

\section{ASSESSMENT OF MEDICATION ERRORS: A CASE STUDY WITH HEALTH PROFESSIONALS IN THE CITY OF CAJAZEIRAS-PB.}

\begin{abstract}
Medication errors are part of the reality world, are present in health institutions and even affect both the public and private sectors. Its occurrence causes serious problems for patients from disability to death. The objective of this study was to identify the causes and risk factors that contribute to the occurrence of medication errors in public hospital. We conducted an exploratory study with a qualitative approach in a public hospital in the city of Cajazeiras-PB. For data collection was used a structured questionnaire with open and closed questions, open questions was used on a digital recorder. After the recordings, interviews were transcribed. The sample was composed of 34 nurses. For data analysis methodology was used to Triviños (2006). The results show that the majority of respondents were female, aged predominantly between

\footnotetext{
${ }^{1}$ Enfermeira Graduada pela Faculdade Santa Maria, Pós-graduada em Enfermagem Clínica Médico-Cirurgica pelo Centro Universitário São Camilo; e Enfermagem do Trabalho pela Faculdades Integradas de Patos (FIP). email:julianaaa100@ yahoo.com.br.

${ }^{2}$ Médica pela Universidade Federal do Ceará. loreninhaloris@ hotmail.com

${ }^{3}$ Professora Doutora do Departamento de Ciências Domésticas/ UFRPE. joseanasaraiva@yahoo.com.br

${ }^{4}$ Professor Mestre do Departamento de Fisiologia e Farmacologia da Universidade Federal do Ceará (UFC).
} 
20 and 29 years, had worked less than 2 years $(44.1 \%), 44.1 \%$ had completed the 2 nd degree and $764 \%$ with income between 1-3 wages. For most respondents, the medication error is associated with illegible handwriting medical, work overload and lack of theoretical and practical knowledge. The handwriting on prescriptions medical hampers the work of nursing, which necessitates a change in the system, through the use of electronic prescriptions, most hiring professionals, conducting refresher courses, all these measures taken in order to reduce or prevent mistakes.

Keywords: Error, Medication, Nursing.

\section{Introdução}

São muitos os estudos realizados acerca da temática de erros de medicação, contudo, devido à falta de notificação das ocorrências destes erros, torna difícil solucionar o problema. A não notificação ocorre principalmente pelo fato de expor o profissional ao constrangimento, mediante a situação de erro, e a punição e/ou demissão no momento em que se relata o erro de medicação.

Os estudos realizados têm evidenciado que a sub-notificação de tais erros resulta no comprometimento da assistência prestada ao paciente, principalmente a prestada pelo setor de enfermagem, que é responsável pela última fase do processo de medicação, isto é, o preparo e administração de medicamentos. Sendo estes profissionais, os responsáveis pela fase do processo de medicação, torna-se necessário verificar e identificar a existência de erros de medicação nas fases anteriores, ou seja, na prescrição e dispensação de medicamentos (MIASSO et al., 2006).

A sub-notificação dos erros dificulta o conhecimento dos reais índices de erros de medicação, tornando assim difícil a detecção dos problemas existentes no sistema e na equipe profissional que atua no atendimento aos pacientes, o que favorece a demora na tomada de decisões quanto a medidas que poderiam ser implementadas para redução dos erros de medicação.

Bohomol e Ramos (2006), evidenciaram que 44.000 causas de morte nos hospitais americanos estavam relacionadas a eventos iatrogênicos. A ocorrência de males provocados pela ação do médico ou pelo tratamento por ele prescrito atingiu índices tão altos, que chegaram a exceder o número de mortes por acidentes com carros (43.458), com câncer de mama (43.397) e com Síndrome da Imunodeficiência Adquirida - AIDS (16.516). Silva e Cassiani (2004), ressaltam que não apenas nas unidades hospitalares, mas também nas unidades básicas de saúde, tornam-se necessárias a existência de sistemas de medicações que funcionem eficazmente. Para tanto, a integração e participação de todos os profissionais de saúde é fundamental, tendo em vista prestar um serviço de qualidade e, por conseguinte, reduzir os índices de eventos iatrogênicos.

Nesse sentido, esse estudo tem como objetivo identificar as causas e os fatores de risco que contribuem para a ocorrência de erros de medicação em uma instituição hospitalar pública, através da caracterização sócio-demográfica dos participantes da pesquisa, identificar a percepção que os profissionais da saúde têm sobre erro de medicação e os elementos considerados contribuintes para a ocorrência destes.

Esta pesquisa contribuirá, de forma significante, para que se possam desenvolver novos estudos sobre erros de medicação no nordeste, para que futuramente venham a preencher a lacuna existente no desenvolvimento de pesquisas acerca da temática nessa região. Bem como, conscientizar os profissionais da área da saúde sobre os fatores contribuintes para à problemática, tendo em vista colaborar para evitar ou minimizar os índices dos erros de medicação.

O estímulo para trabalhar essa temática surgiu a partir de um trabalho desenvolvido anteriormente sobre a importância dos "cinco certos" (paciente certo, medicamento certo, hora certa, dose certa e via certa), no preparo e administração de medicamentos. Constatou-se que o não uso dos cinco certos nos campos de estágios curriculares e extracurriculares favorece a ocorrência dos erros de medicação. Inúmeras foram às interrogações, que nos estimularam a desenvolver um estudo voltado para essa temática, dentre elas "Quais os elementos que favorecem para que os erros ocorram?", "Por que não se ouve falar em erros de medicação 
no ambiente hospitalar?" "Será que eles ocorrem?", "O que os profissionais da saúde consideram ser um erro de medicação?”. Então, em busca de responder aos nossos questionamentos, desenvolvemos este trabalho.

\section{Método}

\section{Desenho do Estudo}

O presente estudo caracterizou-se por percorrer a trajetória metodológica da pesquisa qualitativa, com abordagem descritiva voltada para uma de suas subclassificações: Estudo de Caso. Esta foi uma pesquisa de campo, que segundo Andrade (2003a), é o tipo de pesquisa que se caracteriza pela observação dos fatos tal como ocorrem na realidade, onde o pesquisador efetiva a coleta de dados "em campo", ou seja, diretamente no local da ocorrência dos fenômenos. Andrade (2003b), conceitua o estudo de caso, como o estudo de determinados indivíduos, profissões, comunidades, instituições, realizado com a finalidade de obter generalizações.

\section{Local de Estudo}

A pesquisa foi realizada em um hospital público na cidade de Cajazeiras-Paraíba.

\section{Seleção dos Voluntários}

Os voluntários foram selecionados obedecendo aos seguintes critérios de inclusão e exclusão:

I) Critérios de Inclusão:

a) Maior de 21 anos;

b) Ser profissional da instituição;

c) Ser capaz de compreender a natureza e objeto de estudo, apresentando a intenção de cooperar com o pesquisador e agir de acordo com o requerimento do estudo;

d) Anuência para participar do estudo.

II) Critérios de Exclusão:

a) Ser menor de 21 anos;

b) Não desejarem participar do estudo;

c) Estagiários e profissionais voluntários.

\section{População e Amostra}

O hospital apresenta uma equipe de enfermagem composta por 18 enfermeiros, 39 técnicos e 37 auxiliares, constituindo uma equipe formada por 94 profissionais. Para participação do estudo a amostra foi constituída de 15 profissionais de enfermagem, 18 técnicos de enfermagem e 1 auxiliar de enfermagem. A amostra foi determinada a partir dos critérios de inclusão e exclusão, sendo constituída por $44,1 \%$ dos profissionais de enfermagem e 55,8\% pela equipe de enfermagem (técnicos e auxiliares de enfermagem).

\section{Instrumento de Coleta de dados}

Para a coleta de dados foi utilizado um questionário estruturado, dividido em dois blocos, no primeiro foi abordado a caracterização sócio-demográfica dos entrevistados, e o segundo, constituído de perguntas subjetivas que procuraram conhecer a percepção que os profissionais da saúde têm sobre erro de medicação e os elementos contribuintes para a ocorrência destes. 


\section{Coleta de Dados}

A coleta de dados ocorreu no primeiro semestre de 2008, mais precisamente nos meses de fevereiro e março.

Para efetivar a coleta de dados, foi solicitado primeiramente à coordenação do Curso Bacharelado em Enfermagem da Faculdade Santa Maria, localizada na cidade de Cajazeiras - PB, um ofício, visando apresentar a diretora administradora do hospital, no qual foi desenvolvido.

Seguida a apresentação dos objetivos da pesquisa a responsável pela instituição, e o recebimento do parecer do Comitê de Ética aprovando o projeto foi dado o início do processo de coleta de dados propriamente dito.

No hospital, os profissionais determinados como amostra do estudo conheceram os objetivos da pesquisa e tiveram a livre decisão de aceitar ou não participar do estudo. Os que aceitaram participar assinaram o Termo de Consentimento Livre e Esclarecido. Após, foi realizado a entrevista, por meio de gravação, com a utilização de um gravador digital, estas tendo em média duração de 2 a 4 minutos, onde em seguida foram transcritas na íntegra, imediatamente após o seu término. Foram mantidos o sigilo das informações e o anonimato dos entrevistados, passando todos os entrevistados a serem identificados por nomes de antibióticos, e finalmente após cada entrevista foram feitos os agradecimentos a cada participante.

\section{Posicionamento Ético do Pesquisador}

Para realização desta pesquisa levou-se em consideração a prática preconizada no Brasil em 1996, através da Resolução 196/96, que trata da pesquisa envolvendo seres humanos, a qual atende ao princípio ético de autonomia, principalmente no que se refere ao consentimento e esclarecimento aos participantes da pesquisa (Brasil, 1996).

Em conformidade com a resolução supracitada, ressaltamos que em hipótese alguma foi divulgado nesta pesquisa o nome das pessoas envolvidas. Para garantia do sigilo dos entrevistados, cada participante foi identificado por nome de medicamentos antibióticos, cabendo lembrar que a categoria do profissional, também não foi divulgada.

\section{Análise e Discussão dos Dados}

Os dados obtidos foram compilados e analisados descritivamente com base em um enfoque no método qualitativo, a partir dos dados primários que foram coletados através de informações contidas no instrumento, e discutido sob a luz da literatura pertinente ao tema.

Os dados coletados foram processados no programa estatístico Excel para construção de banco de dados referentes às variáveis quantitativas e expresso em figuras e tabelas com auxílio da planilha Microsoft Office Excel 2000.

Os dados foram analisados descritivamente mediante a abordagem qualitativa. Os dados que caracterizaram os participantes do estudo foram tratados com base na distribuição de frequência e apresentados em tabelas sendo discutidos em seguida á luz da literatura pertinente ao tema em estudo.

Os dados discursivos foram analisados por meio da técnica interpretativa, dos quais seguiram os seguintes passos:

$1^{\circ}$ Leitura das respostas e separação por categorias;

$2^{\circ}$ As categorias foram escolhidas pela apreensão da ideia central que perpassou as respostas;

$3^{\circ}$ Escolha de uma resposta que melhor representa as outras da mesma categoria;

$4^{\circ}$ Análise interpretativa dos dados que segundo Trivinos (2006), apoiar-se em três aspectos fundamentais: a) nos resultados alcançados no estudo; b) na fundamentação teórica; c) na experiência pessoal do investigador. 


\section{Resultados e Discussão}

A seguir são apresentados os resultados analisados e discutidos a partir das informações fornecidas pelos profissionais entrevistados de um hospital público da cidade de Cajazeiras - PB, mediante a aplicação do instrumento de coleta de dados, elaborado pelos pesquisadores.

Tabela 1 - Caracterização da população em relação aos dados sócio-demográficos

\begin{tabular}{lll}
\hline Dados Sócio - Demográficos & n & \% \\
\hline Sexo & & \\
Masculino & 06 & 17,6 \\
Feminino & 28 & 82,3
\end{tabular}

\section{Faixa etária}

30-39

61,8

40-49

$05 \quad 14,7$

50-59

$07 \quad 20,6$

$01 \quad 2,9$

\section{Categoria do profissional}

Enfermeiro (a)

$15 \quad 44,1$

Técnico de enfermagem

$18 \quad 53,9$

Auxiliar de enfermagem

$01 \quad 2,9$

\section{Tempo de trabalho}

$\begin{array}{lll}\leq 2 \text { anos } & 15 & 44,1 \\ 3 \text { a } 6 \text { anos } & 06 & 17,6 \\ \geq 8 \text { anos } & 09 & 26,5 \\ \geq 20 \text { anos } & 04 & 11,8\end{array}$

\section{Grau de escolaridade}

$1^{\circ}$ Grau Incompleto

$01 \quad 2,9$

$2^{\circ}$ Grau Completo

$15 \quad 44,1$

Superior Incompleto

$03 \quad 29,4$

Superior Completo

$10 \quad 14,7$

Especialização

$05 \quad 8,8$

Renda

Menos de 1 salário

De 1 a 3 salários

$04 \quad 11,8$

De 4 a 7 salários

$26 \quad 76,4$

Fonte: dados da pesquisa

A tabela 1 nos mostra que dentre os entrevistados, 82,3\% estão representados pelo sexo feminino, e $17,6 \%$ pelo masculino. A prevalência do sexo feminino no trabalho da enfermagem está muito voltada para figura da mulher como cuidadora, principalmente pela própria imagem que a profissão é representada: Florence Nightingale. De acordo com Silva, Silva, Gobbo e Miasso (2007), o predomínio de mulheres na profissão, está justamente ligado ao próprio desenvolvimento da enfermagem, a figura das irmãs de caridade na direção dos serviços hospitalares e os cuidados da enfermagem na Santa Casa de misericórdia do Rio de janeiro. 
Podemos verificar que a maioria dos entrevistados $(61,8 \%)$ deste estudo encontram-se na faixa etária entre 20 e 29 anos, e que $44,1 \%$ dos participantes tem tempo de trabalho igual e/ou superior a dois anos. Isso nos mostra que a um predomínio de profissionais recém formados e/ou com pouco tempo de trabalho (experiência), fator este contribuinte para se evitar os erros de medicação, pois por estes estarem com os conhecimentos mais recentes, irão desenvolver os procedimentos de maneira mais cuidadosa e atenciosa, prevenindo erros.

Em um estudo realizado por Silva, Silva, Gobbo e Miasso (2007), observou-se que a maior propensão ao erro estava relacionada aos enfermeiros experientes, pelo fato que estes tem de julgarem que suas ações e decisões são mais corretas referentes à administração de medicamentos, mesmo quando estão realmente errados.

O estudo evidencia que $(44,1 \%)$ dos entrevistados possuem o $2^{\circ}$ grau completo, isso por se observar a prevalência de técnicos de enfermagem na equipe. Dentre os enfermeiros, evidenciou-se que $8,8 \%$ deles já tem além da graduação, uma especialização.

Embora o enfermeiro seja responsável pelo preparo e administração de medicamentos, sabe-se que esta é uma atividade delegada aos técnicos de enfermagem, profissionais estes que possuem pouco embasamento teórico quanto aos medicamentos utilizados e suas interações, o que contribui para que os erros ocorram, pois o desconhecimento da farmacologia se torna um elemento fundamental para o erro de medicação. Sendo necessária a presença de um enfermeiro em cada setor do hospital, para que os profissionais técnicos e auxiliares de enfermagem possam sanar as dúvidas presentes durante o preparo e administração de medicamentos.

Em um estudo realizado por Miasso et al., (2006), para identificar problemas relacionados aos erros de medicações, evidenciou-se que a falta de conhecimento sobre o medicamento, conhecimentos errados, insuficientes ou inexistentes relativos aos medicamentos, como: uso, dose, via, preparação e administração, são elementos determinantes na ocorrência dos erros de medicação.

Nesse estudo 76,4\% dos entrevistados apresentam renda salarial entre 1 a 3 salários, sendo que 11,3\% dos participantes se caracterizam por receberem menos de 1 salário e de 4 a 7 salários. É notório que a dedicação à profissão está muitas das vezes associada aos vencimentos que o profissional recebe, este irá variar de acordo com seu grau de formação e atuação na instituição. $O$ ganho insuficiente associado a elevadas cargas de trabalho e plantões carregados atuam de maneira negativa na assistência prestada aos pacientes, pois o profissional trabalha com insatisfação, desmotivado, alterando assim seu desempenho nas ações dentro da instituição.

De acordo com Carvalho e Vieira (2002), existem inúmeros fatores que influenciam a ocorrência de erros humanos, fatores ambientais (barulho, agitação, calor, estímulos visuais), psicológicos (tédio, frustração, ansiedade, estresse) e fisiológicos (fadiga, sono, sobrecarga de trabalho, uso de drogas, álcool, doenças), sendo os principais responsáveis pela quebra de barreiras de defesa, pois por afetarem todos os processos cognitivos, podem causar um grande número e variedade de erros, que resulta em ações não seguras.

\section{Análise qualitativa}

Para melhor compreensão da análise, os discursos foram categorizados e serão apresentados na seguinte sequência: I) Erros de medicação, II) Elementos que favorecem ao erro de medicação, III) Identificação da ocorrência de erros de medicação, IV) Atitude na observância de um erro de medicação, V) Conhecimento dos "5 certos" para se preparar e administrar medicamento, VI) Dificuldade para ler e entender as prescrições de medicamento e VII) A importância da presença de um farmacêutico no hospital.

Seguindo o princípio ético da Resolução 196/96, a qual dispõe do princípio do anonimato do nome do entrevistado, decidimos identificar cada profissional com nome de medicamentos antibióticos, tais como: ceftriaxona, ampicilina, amoxacilina, norfloxona, eritromicina, cefopenazona, ceftazidima, sulfadiazina, sulfadiazima, cefprozil, roxitromicina, cefloxitima, oxacilina, cefprime, cefasolina, ofloxacina, vancomicina, cefpozil, subactâno, imipirem, cefadroxila, penicilina, amicacina, roxitromicina, cefuroxima, perfoxacina, lincomicina, trimetropina, perfloxacina, rifampicina e cefadroxila. 


\section{I) Erro de medicação}

Os depoimentos dos profissionais apontam que, o erro de medicação é resultado de um preparo e administração de medicamentos incorreta, onde expõem o paciente ao uso de drogas que não tem indicação para o seu quadro clínico, essa troca de medicamento ocorre muitas das vezes pela não compreensão da caligrafia médica, o que contribui para o desenvolvimento de complicações no paciente, gerando assim um quadro irreversível e levá-lo ao óbito. Como se pode observar a partir dos discursos dos profissionais:

"O erro de medicação é um procedimento que pode complicar a vida do paciente, e que é irreversivel" (Ampicilina).

"É a administração incorreta, é um erro que já pode vim desde o preparo da medicação, é o contrário dos cinco certos" (Amoxacilina).

"É quando você administra no paciente errado, ou então faz uma medicação que não é para ser feita em determinado paciente" (Eritromicina).

"A questão da medicação muito parecida, como no caso da cefalotina com ceftriaxona muitos técnicos e auxiliares não prestar atenção e podem fazer, se ta prescrito ceftriaxona ele faz. cefalotina e ai é um erro de medicação" (Ceftazidima).

"É a troca da medicação, você substitui um medicamento por outro por falta de entender a letra do médico" (Norfloxona).

O erro de medicação é qualquer erro no processo de prescrição, dispensação ou administração dos medicamentos, podendo ou não trazer consequências adversas ao paciente, que contribuem para depreciação profissional e podem também, aumentar os custos das internações hospitalares (Bohomol \& Ramos, 2007). Para Toscano, Blum e Neves (2005), o erro de medicação um evento evitável que, de fato ou potencialmente, pode levar ao uso inadequado de medicamento, podendo vir a lesar ou não o paciente, e pode estar relacionado à prática profissional, ao produto usado, procedimento, má comunicação na prescrição, rótulos, embalagens, preparação, dispensação, distribuição, monitoramento, etc.

\section{II) Elementos que favorecem ao erro de medicação}

Toda instituição está susceptível a desencadear algum erro durante a realização das ações, embora estes não sejam aceitos no sistema de saúde, observamos que muitos são os elementos que favorecem a ocorrência destes: sobrecarga de trabalho, poucos profissionais para atender uma grande demanda de pacientes, assistência prestada de forma rápida e com pouca eficácia, devido à falta de atenção durante a leitura das prescrições médicas, e a presença do sono durante os plantões noturnos.

Podemos observar todos estes fatores citados na leitura dos discursos abaixo:

"Existe. Acho que a rapidez, muita gente interrompendo, às vezes tem uns dez pacientes aqui para você atender sozinho, ai você fica aperriado, faz uma coisa errada e você nem percebe" (Sulfadiazina).

"É, eu acho que aqui um dos casos mais agravantes é o excesso de paciente para o numero de profissional, você não tem condição, como aqui hoje, uma correria né. Os pacientes querem ser atendidos na hora certa e às vezes corre, e corre o risco de não olhar bem a medicação, o nome do paciente, a prescrição e fazer a medicação errada, as vezes pode até trocar prontuário" (Sulfadiazima).

"Sim, a não fundamentação teoria prática, que o profissional tem, que eu acho que é muito importante você ter a fundamento teórico, ao mesmo tempo a prática de diluição de medicamento para que favoreça o não erro de medicação" (Cefprozil).

"Continuo dizendo ainda a falta de atenção. Porque tendo atenção você não erra" (Roxitromicina). 
"Sim a displicência ou até mesmo a negligência médica, vamos levar também para o lado do sono ou o não entendimento da doença" (Cefloxima).

Os erros podem estar relacionados com fatores individuais, como falta de atenção, lapsos de memória, deficiência da formação acadêmica, inexperiência, etc., mas também, com falhas sistêmicas como: problemas no ambiente, falta ou falha no treinamento, falta de profissionais, falha na comunicação (Miasso et al., 2006). As prescrições inadequadas e ilegíveis geram inúmeras dificuldades ao tentar ler, o que favorece as trocas entre medicamentos de classes farmacológicas diversas e, em consequência causa enormes danos a população (Lyra Júnior, Prado, Abriata \& Pelá, 2004).

Os sistemas devem contar com pessoal adequadamente preparado e supervisionado, comunicações apropriadas, cargas de trabalho razoáveis, comprovações múltiplas de procedimentos, sistemas de garantia de qualidade, assim como locais, equipamentos e abastecimento adequados (Anacleto, Perini \& Rosa, 2007). Segundo Carvalho e Cassiani (2000), na nossa realidade os profissionais de enfermagem assumem dupla jornada de trabalho, com vínculo empregatício em duas ou mais instituições de saúde, o que gera sobrecarga de trabalho, promove fadiga, estresse e desatenção no ambiente de trabalho, predispondo assim a ocorrência de erros de medicação.

A falta de preparo teórico para subsidiar a implementação segura da terapia medicamentosa, constitui uma situação de risco para o paciente, que se atribui a falhas no conhecimento farmacológico. As autoras destacam que o sucesso da terapia medicamentosa depende do conhecimento do diagnóstico do paciente e das indicações do medicamento. A enfermagem por constituir a última etapa do processo de administração de medicamentos, deve ser responsável por conhecer os medicamentos a serem administrados, para que assim não coloque em risco a vida do paciente (Carvalho \& Cassiani, 2000).

\title{
III) Identificação da ocorrência de erros de medicação
}

Sabemos que muitos profissionais já presenciaram algum tipo de erro de medicação. Embora a fase do preparo e administração de medicamentos seja visto de forma simples, é importante que o responsável por desenvolver essa ação disponibilize de conhecimento para desenvolver tal prática, evitando assim que o paciente receba medicações trocadas e/ou sem necessidade.

A partir do discurso dos profissionais podemos observar:

\begin{abstract}
"Sim, o paciente não tinha medicação de flagyl, estava fazendo uso de dobutamina contínua e a técnica administrou um flagyl" (Cefprime).

"Sim, medicação IM que é acima de 2 ml feita no deltóide" (Cefalexina).

"Já, uma medicação que era para ser administrada lentamente e foi administrada muito rápida, causando reações no paciente” (Amoxacilina).

"Já, o paciente estava convulsionando e o técnico não conhecia o nome genérico e administrou a medicação errada, por não conhecer o nome químico” (Ofloxacina).

"Sim, foi quando uma colega administrou $\mathrm{KCl}$ e $\mathrm{NaCl}$ diretamente endovenosa, e ela disse que ninguém tinha falado isso para ela, ou seja, que essa medicação causa a morte no quando administrado diretamente" (Vancomicina).

"Sim, um diclofenaco EV, isso geralmente no tempo de estagiário. Isso é um acidente que geralmente acontece em alguns estágios, que eu já presenciei no meu tempo de estágio, quando eu era estagiário como técnico de enfermagem" (Cefprozil).

"Já, fazer uma decadron dentro de uma cefalotina. Assim, preparar uma decadron seguido do diluente" (Subactano).
\end{abstract}

Embora o desconhecimento sobre os medicamentos seja um motivo importante quando falamos de erros, é importante enfatizar que os erros também acontecem mesmo quando se conhecem os medicamentos. Aqueles que lidam com os medicamentos, sejam os prescritores, farmacêuticos clínicos, dispensadores, administradores, precisam conhecê-los para que possam zelar pela qualidade, custos e resultados terapêuticos dos medicamentos (Ueta, 2005). O escasso conhecimento referente a métodos, vias, locais, ações, dosagens, 
diluições, técnicas de assepsia (inclusive a lavagem das mãos) e utilização adequada de materiais estéreis podem promover considerável parcela de erros no processo de administração de medicamentos (Filho \& Cassiani, 2004).

Os erros colocam em risco a integridade física do cliente/usuário, e também a qualidade dos serviços oferecidos aos mesmos, além de gerar prolongamento da internação, aumento nos custos da hospitalização, necessidade de tratamentos adicionais, exames e procedimentos extras, assim como dor, sofrimento, sequelas, podendo levá-los a morte (Santos, Silva, Munari \& Miasso, 2007).

Observou-se que a sub-notificação também está vinculada ao desconhecimento do que seja efetivamente um erro de medicação além do desconhecimento frente às intercorrências que possam ocorrer com o paciente e com o temor quanto ao seu futuro profissional (Bohomol \& Ramos, 2007).

\section{IV) Atitude na observância de um erro de medicação}

Embora nesse estudo, a maioria dos profissionais afirme que mediante a ocorrência de erros de medicação procuram informar aos demais colegas de equipe, seja o enfermeiro responsável pelo plantão ou médico presente, objetivando evitar maiores complicações no paciente assistido e atuam impedindo a realização de procedimentos inadequados pelos demais colegas. Observamos que muitos ainda temem a notificar o erro, devido ao medo das medidas administrativas atribuídas ao profissional responsável, este sendo um elemento contribuinte para a sub-notificação dos erros e não educação dos profissionais.

Nos discursos seguintes os entrevistados relatam a atitude tomada frente a um erro de medicação:

"Com certeza, eu tomaria uma atitude, se eu presenciei que tava errada aquela medicação, eu chamo o profissional e vou conversar com ela, eu não deixo nem administrar, eu só presenciei assim a preparação, porque eu não deixo administrar" (Imipirem).

"Sim, claro. Tem que se dirigir a chefe geral, porque a gente não pode resolver esse problema, quem tem que resolver é exatamente quem ta acompanhando a pessoa que ta errada é que deve resolver esse problema" (Subactâno).

"A atitude que eu tomaria como profissional da saúde seria chegar junto ao médico, ou então a pessoa que estaria prescrevendo, que eu teria dentro do meu entendimento chegar junto a ele e saber e questionar a medicação, porque eu teria entendimento que não faria bem ao paciente, eu na minha parte ética não taria vigorando a ela, ver o paciente tomar uma medicação que não é cabivel a ele" (Sulfazalazina).

"Com certeza, porque um simples erro, como uma diluição mal feita, pode levar o paciente a óbito” (Penicilina).

"Sim, eu chamaria a pessoa que estava cometendo o erro e conversava, tentando ensinar da forma correta, para que a pessoa nunca mais cometesse o mesmo erro, pois a ocorrência deste pode comprometer até sua vida profissional" (Amoxacilina).

A equipe de enfermagem constitui a ponta final do sistema de medicação, fato que aumenta a sua responsabilidade, diante da exposição ao erro. Seu ato marca a transição de um erro previsível para ser real, tendo como agravante neste processo, é que, mediante a ocorrência de erros de medicação, frequentemente não se dá ênfase na educação, mas a punição, levando a sub-notificação dos casos, com consequente prejuízo no conhecimento dos fatores de risco e facilitando a repetição do erro (Santos, Silva, Munari \& Miasso, 2007).

$\mathrm{Na}$ busca pela amenização dessa problemática, pesquisadores têm indicado a necessidade de capacitação do profissional que administra medicamentos como intervenção fundamental para minimização de tais ocorrências, procurando por meio da realização destes o fornecimento de uma administração segura e eficaz e com nível de excelência, o que proporcionará tanto ao profissional como ao paciente, benefícios de incontestável valor (Filho \& Cassiani, 2004). 
As medidas administrativas tomadas com a maioria dos profissionais envolvidos, segundo estudos realizados por Carvalho \& Cassiani (2002), são: advertência verbal, notificação da ocorrência, orientação, advertência escrita e demissão, todos seguidos nessa ordem. Na ocorrência de um erro é fundamental que o profissional aja com honestidade, sem medo das punições, o que facilita o relato do incidente para que sejam tomadas as devidas providências o mais rápido possível, em relação ao paciente, família e profissional envolvido, pois diante da ocorrência a atitude do profissional pode fazer uma grande diferença, pois os benefícios ou complicações do erro vão depender da conduta tomada por todos os envolvidos.

\section{V) Conhecimento dos "5 certos" para se preparar e administrar medicamento}

Para o preparo e administração de medicamentos é de extrema importância o conhecimento dos cinco certos, este sendo considerado requisito básico para um procedimento eficaz e com resultados esperados de uma administração segura. Alguns profissionais não lembram esses requisitos, outros atribuem esses a outras necessidades também relevantes durante o preparo e administração de medicamentos (lavagem das mãos, checar administração do medicamento, proteger a medicação, dentre outros), porém deve-se considerar que os cinco certos estão relacionados ao princípio do paciente certo, medicação certa, dose certa, hora certa e via certa, sabendo que os erros de medicações podem estar relacionados a ausência destes elementos nas prescrições medicamentosas.

Depoimentos dos profissionais a cerca dos cinco certos:

"Preparar a medicação, conferir a medicação, certificar medicação do paciente, administrar medicação, checar administração do medicamento" (Amicacina).

"Sim, paciente certo, dose certa, hora certa, via certa, medicamento certo"

(Ofloxacina).

"Infelizmente não lembro" (Roxitromicina).

"Lavar as mãos primeiro, observar bem o medicamento que vai fazer, proteger a medicação, fazer a assepsia antes de fazer a medicação, prestar bem atenção na hora que tu vai administrar"(Subactâno).

A administração de medicamentos é uma das atividades mais sérias e de maior responsabilidade da enfermagem e para a sua execução é necessário a aplicação de vários princípios científicos que fundamentem a ação do enfermeiro, de forma a prover a segurança do paciente. Para realizar a administração de medicamento com eficiência e responsabilidade, faz-se necessário que a enfermagem conheça os métodos e técnicas de administração, a ação dos medicamentos no organismo, as vias de administração e eliminação, as doses máximas e terapêuticas, os efeitos tóxicos e os efeitos colaterais (Silva, Silva, Gobbo \& Miasso, 2007).

Inúmeros medicamentos são lançados no mercado, em consequência do avanço tecnológico da indústria farmacêutica, o que torna a administração de medicamentos uma atividade que requer cada vez mais conhecimento dos profissionais de saúde que atuam nessa prática. Embora o conhecimento farmacológico seja princípio básico vários autores tem apontado o escasso conhecimento de farmacologia, fisiologia e anatomia, o despreparo dos profissionais na administração de medicamentos tem causado sérias consequências aos pacientes, muitas vezes debilitantes, desencadeando reações indesejadas, como complicações advindas de procedimentos técnicos inadequados ou incorretos decorrentes dos erros de medicação. Para assegurar uma administração de medicamento correta, ausente de falhas algumas estratégias são utilizadas e observadas, como os cinco certos: medicamento certo, paciente certo, dose certa, via de administração certa e horário certo (Carvalho \& Cassiani, 2000). 


\section{VI) Dificuldade para ler e entender as prescrições de medicamento}

A prescrição medicamentosa é o elemento essencial para que se possa ser dispensada a medicação da farmácia e para ser preparada toda a medicação de um paciente. Na maior parte das vezes esta atua dificultando o trabalho dos profissionais que dependem dela, pois a letra ilegível dos médicos leva ao surgimento de dúvidas quanto ao que foi prescrito, podendo ocasionar erros de medicação quando alguns dos profissionais tentam decifrar o que está escrito.

A partir do discurso dos profissionais podemos observar:

"Depende do médico, porque eles escrevem as coisas só pela metade, não escreve o nome do medicamento completo" (Cefuroxima).

"Sim, a maioria dos médicos não tem uma letra legível, ai fica difícil para nossa interpretação" (Cefalexina).

"Não, às vezes não. Depende do médico, tem médico que enrola tudo, ai eu pergunto para as meninas alguma coisa, dá para desenrolar por causa do costume" (Sulfadiazina).

"Às vezes, como aqui os médicos, até antes do concurso, os médicos eram sempre os mesmos então a gente já sabe as medicações que eles prescrevem, porque é uma rotina, geralmente nunca muda, não sei ler a letra deles mas pela rotina de ser sempre aquilo, a gente já sabe, mas a letra é horrível, mas a pessoa vai deduzindo porque a gente já sabe a medicação que ele prescreve, mas quando a gente não entende pergunta a ele"

(Perfoxacina).

Inúmeros são os transtornos acarretados nas atividades de farmácia e da enfermagem, com idas e vindas, condições estas proporcionadas por uma caligrafia ruim do médico, que ocasiona atrasos e gastos desnecessários na assistência fornecida ao cliente. Esta situação fica ainda mais agravante quando este profissional encontra-se ausente no serviço, pois leva aos demais profissionais a interpretar o que está escrito nas prescrições de acordo com suas experiências e dispensar o medicamento de acordo com o que acredita estar prescrito. $\mathrm{O}$ fato de a prescrição ser manual aumenta a incidência de erros, devido a grafia médica ser na maioria das vezes de difícil compreensão, esta atua facilitando a ocorrência de erros durante a interpretação, além de fazer com que a equipe de enfermagem e de farmácia tenham trabalho extra ao tentar decifrar o que nelas está escrito (Miasso et al., 2006).

A letra ruim, ilegível ou mal escrita, associada aos nomes de medicamentos semelhantes, podem conduzir os profissionais de enfermagem ao erro, pois prescrições médicas ilegíveis são consideradas situações de risco para ocorrência de erros de medicação, portanto os enfermeiros e farmacêuticos não devem tentar decifrar as caligrafias ruins ou ilegíveis dos demais profissionais e sim consultá-los, visando esclarecimentos sobre a prescrição, evitando assim as dúvidas e más interpretações (Carvalho \& Cassiani, 2000).

As prescrições de medicamentos são o início de uma cadeia de ações que levará o medicamento não podendo constituir um fator exacerbado para o erro ou potencial para o erro na medicação, pois a carência dos médicos a cerca da farmacologia dos medicamentos prescritos, aumenta ainda mais a probabilidade da ocorrência de iatrogênicas. É necessário que o profissional que participa da medicação de um paciente conheça e atue na corrente que se forma nos desempenhos das tarefas, para que se desenvolva seu papel com segurança, consciência, responsabilidade e eficiência (Miasso, Grou, Cassiani, Silva \& Fakin, 2006).

Um dos meios utilizados para diminuir os erros de administração de medicamentos é a substituição das prescrições manuais, na maioria das vezes ilegível, pela prescrição informatizada, um sistema no qual o médico redige a prescrição diretamente no computador, enviando para a farmácia por via eletrônica, esse procedimento reduz as dificuldades em relação a caligrafia médica, prescrições ambíguas e incompletas, pois esses tipos de prescrições não conseguem ser enviadas para a farmácia, pois o sistema trava quando na presença de informações incompletas (Anacleto, Perini \& Rosa, 2007). 


\section{VII) É importante a presença de um farmacêutico no hospital}

Diversos são os profissionais que atuam em um hospital, dentre eles o farmacêutico que é o responsável pela dispensação de todos os medicamentos para todos os setores do hospital. Este deve ter total conhecimento das medicações e seus efeitos colaterais, ele atua sendo um facilitador do trabalho da equipe de enfermagem, pois sana muitas das dúvidas resultantes das prescrições médicas informando sobre substituição de medicações, ajudam muitas vezes até aos próprios médicos na escolha de determinados fármacos, por terem um conhecimento teórico bem mais abrangente que os demais profissionais.

Nos discursos seguintes os entrevistados relatam sobre a importância do farmacêutico no hospital:

"Sim, porque as vezes alguns médicos não tem tanta certeza de como se procede com alguns medicamentos, principalmente a forma de diluição, as que são menos usadas e ai os efeitos muitas vezes não são os esperados" (Lincomicina).

"Sim, porque na maioria das vezes, certos médicos cometem erros absurdos, e tendo a presença desse profissional ajuda muito no trabalho da enfermagem que é quem administra esses medicamentos prescritos" (Cefeprime).

"Com certeza, porque às vezes o farmacêutico entende tudo de medicação, acontece algum erro de medicação, as vezes o médico prescreve a medicação errada, o farmacêutico vai na farmácia e ele mesmo sabe e já manda a medicação correta, quando o erro é médico" (Sulfadiazina).

"É importante porque tanto lá na farmácia, como pra gente. Eu tenho varias dúvidas de medicamentos, eu vou lá e pergunto a ela pra que é que serve, o que é que faz,o que inibe, se é um betabloqueador. Os médicos novos, eles estão prescrevendo outras coisas ai a gente tem que ir lá na farmácia pedir a medicação e pra que serve, porque no caso quando o médico não tiver aqui a gente sabe como intervir na medicação"

(Perfloxacina).

"Considero importante, porque ele pode até orientar a questão de efeito colateral na medicação e também tirar dúvida na questão de medicação genérica, que aqui tem muita, que o médico prescreve de um jeito e tem o original e o genérico, ai a gente pergunta essa questão ao farmacêutico" (Cefadroxila).

O farmacêutico atende o paciente diretamente, avalia e orienta em relação a farmacoterapia prescrita pelo médico, por meio da análise de suas necessidades relacionadas aos medicamentos e detectando problemas relacionados aos medicamentos, consolida assim a relação existente entre a prática e o conhecimento teórico na atuação farmacêutica, promovendo, sobremaneira, saúde, segurança e eficiência na assistência prestada (Oliveira, Oyakawa, Miguel, Zanin \& Montrucchio, 2005).

Nas farmácias, os farmacêuticos são responsáveis pela dispensação de medicamentos com precisão e para isso devem desenvolver e seguir procedimentos que previnam erros e garantam a distribuição de todos os medicamentos com segurança aos pacientes, para isso deve manter a prescrição e a medicação dispensada juntas durante todo o processo, evitando assim trocas de medicamentos (Anacleto, Perini \& Rosa, 2007).

Um dos problemas ligados a dispensação de medicamentos é que, muitas vezes essa tarefa pode estar sendo desenvolvida por leigos, que não apresentam nenhuma formação para orientar sobre a farmacoterapia. Alguns estudos demonstram que a substituição das prescrições manuais pelas eletrônicas pode minimizar, mas não eliminar totalmente a possibilidade de riscos de PRM. Cabe enfatizar ainda, que mesmo com um sistema informatizado, o farmacêutico ainda é essencial para a orientação sobre o uso correto do medicamento e esclarecimento de dúvidas referente ao tratamento (Lyra Jùnior, Prado, Abriata \& Pelá, 2004). 


\section{Referências}

ANACLETO, T. A.; PERINI, E.; ROSA, M. B. (2006). Prevenindo erros de dispensação em farmácias hospitalares. v.18, $\mathrm{n}^{\circ} 7 / 8$, p.32-35. Disponível em: www.cff.org.br/revistas/54/inf32a36.pdf. Acesso: $23 / 10 / 2007$

ANDRADE, M. M. Introdução a Metodologia do Trabalho Científico. Pesquisa Científica: Noções introdutórias. $6^{a}$ edição. Editora: Atlas S. A. São Paulo, 2003 (a).

ANDRADE, M. M. Introdução a Metodologia do Trabalho Científico. Métodos e técnicas de pesquisa . $6^{\mathrm{a}}$ edição. Editora: Atlas S. A. São Paulo, 2003 (b).

BOHOMOL, E.; RAMOS, L. H. Percepção sobre o erro de medicação: uma análise de respostas da equipe de enfermagem. Revista Latino Americana de Enfermagem. v. 14, n06, Ribeirão Preto, nov./dez, 2006.

BOHOMOL, E.; RAMOS, L. H. Erro de medicação: importância da notificação no gerenciamento da segurança do paciente. Revista Brasileira de Enfermagem. v. 60, nº1, Brasília.Janeiro/fevereiro, 2007.

BRASIL, Ministério da Saúde. Conselho Nacional de Saúde. Comissão Nacional de Ética em pesquisa. Normas para pesquisa envolvendo seres humanos: (Res. CNS 196/96 e outros). Brasília (DF), 1996.

CARVALHO, V.T.; CASSIANI, S.H.B. Erros na medicação: análise das situações relatadas pelos profissionais de enfermagem. Medicina. Ribeirão Preto, 2000.

CARVALHO, V.T.; CASSIANI, S.H.B. Erros na medicação e consequiências para os profissionais de enfermagem e clientes: um estudo exploratório. Revista Latino Americana de Enfermagem. v.10, $n^{\circ} 14$, Ribeirão Preto, julho/agosto, 2002.

CARVALHO, M.; VIEIRA, A.A. Erro médico em pacientes hospitalizados. Jornal de Pediatria. v.78, n04, 2002.

FILHO, P. C. P. T.; CASSIANI, S. H. B. Administração de medicamentos: aquisição de conhecimentos e habilidades requeridas por um grupo de enfermeiros. Revista Latino Americana de Enfermagem. v.12, $\mathrm{n}^{\circ}$ 3, Ribeirão Preto, Maio/ Junho, 2004.

LYRA JÚNIOR, D. P.; PRADO,M.C.T.A.; ABRIATA, J.P.; PELÁ, I.R. As prescrições médicas como causadoras de risco para problemas relacionados com os medicamentos. Seguim Farmacoter. 2004. Disponível em: www.farmacare.com. Acesso em: 15/02/2008, as 09:40 horas.

MIASSO, A. I.; SILVA, A.E.B.C.; CASSIANI, S.H.B.; GROU, R.; OLIVEIRA, R.C.; FAKIH, F.T. O processo de preparo e administração de medicamentos: identificação de problemas para propor melhorias e prevenir erros de medicação. Revista Latino Americana de Enfermagem. v. 14, no 3. P. 354-363. Ribeirão Preto. Maio/ Junho, 2006.

MIASSO, A.I.; GROU, C.R.; CASSIANI, S.H.B.; SILVA, A.E.B.C.; FAKIN, F.T. Erros de medicação: tipos, fatores causais e providências tomadas em quatro hospitais brasileiros. Revista da Escola de Enfermagem da USP. v. 40, nº 4. São Paulo. Dezembro, 2006.

OLIVEIRA, A.B.; OYAKAWA,C.N.; MIGUEL, M.D.; ZANIN,S.M.W.; MONTRUCCHIO, D.P. Obstáculos da atenção farmacêutica no Brasil. Revista Brasileira Ciências Farmacêuticas v.41, no 4. São Paulo. Outubro/dezembro, 2005. 
SANTOS, J.O.; SILVA, A.E.B.C.; MUNARI, D.B.; MIASSO,A.I. Sentimentos de profissionais de enfermagem após a ocorrência de erros de medicação. Acta Paul. Enferm. v.20,nº 04. São Paulo. Outubro/dezembro, 2007.

SILVA, A. E. B. C.; CASSIANI, S. H. B. Administração de medicamentos: uma visão sistêmica para o desenvolvimento de medidas preventivas dos erros de medicação. Revista Eletrônica de Enfermagem. v. $06, \mathrm{n}^{\circ} 2 ., 2004$.

SILVA, B. K.; SILVA,J.S.; GOBBO, A.F.F.; MIASSO, A.I. Erros de medicação: condutas e propostas de prevenção na perspectiva da equipe de enfermagem. Revista Eletrônica de Enfermagem. v. 09, $\mathrm{n}^{\circ}$ 03,p. 712-723, 2007.

TOSCANO, V. G.; BLUM, V. F.; NEVES, J. R. L. Responsabilidade ética na prescrição e troca de medicamentos. Revista da Associação Médica Brasileira. v. 51, nº 06. São Paulo. Nov./Dez, 2005.

TRIVINOS, A. N. S. Introdução à pesquisa em ciências sociais: a pesquisa qualitativa em educação. São Paulo: Atlas, 2006.

UETA, J. Erros de medicação: outros focos de reação ao problema. Pharmacia Brasileira. Outubro/novembro/dezembro, 2005. Disponível em:

www.cff.br/revistas/50/024\%20a\%20036.pdf. Acesso em: 20/04/2008. 